\title{
IOT BASED AUTOMATING THE IRRIGATION SYSTEM
}

\author{
M. ZAHIR AHMED ${ }^{1}$, SHAIK. ABDUL MUNEER ${ }^{2}$, MOHAMMED WAAIZ $^{3}$ \& \\ N.UMA MAHESWARA REDDY ${ }^{4}$ \\ ${ }^{1,2}$ Lecturer in Physics, Osmania College (A), Kurnool, Andhra Pradesh, India \\ ${ }^{3}$ Assistant Professor of Physics, Government College for Men, Kurnool, Andhra Pradesh, India \\ ${ }^{4}$ Lecturer in Physics, S.V.B. Government Degree College, Koilkuntla, Andhra Pradesh, India
}

\begin{abstract}
In India, agriculture plays a vital role in our day to day life and the Future India depends on our agriculture. Agriculture depends on soil quality, rainy season to make the crops to grow. The field of agriculture farmers face major issues in watering their crops. Actually in agriculture system farmers have to arrange water pump facility and wait till complete land to be in wet condition. In this process farmers are loss their valuable time. If irrigating water to the crop in excess which contains increases the concentration of soil. Result is crops to destroy. In this paper, automation of irrigation system based on Node MCU module is proposed and implemented. This system controls the exact condition of water level of the agriculture land and also implemented advanced system i.e. whenever water is available in pipes only in this condition start motor automatically for power saving purpose and it sends status of irrigation system SMS by Node MCU module

KEYWORDS: Node MCU, IoT, irrigation system, Soil Moisture Sensor Module,16×2 LCD Display, Relay control
\end{abstract}

Received: May 09, 2020; Accepted: Jun 29, 2020; Published: Jun 30, 2020; Paper Id.: IJMPERDJUN2020235

\section{INTRODUCTION}

Smart irrigation system as shown in fig. 1 is an experimental process, it is providing water to the crop this is the main aim of the agricultural system. This system would decrease the workload of the farmer and saves time. Also, it maintains the quality of soil for better growth. Henceforth with the development of innovation it was conceivable to outline frameworks that killed the immediate inclusion of the agriculturist concerning watering system of their fields [1]. The complete mechanical design of watering system is controlled by controller. When water is reaches sufficient plant level submersible motor is automatic ON/OFF by using relay module.

A notification alert in agriculture watering system framework has two noteworthy advancements behind it, essential being the "Notification" and optional one is the controller or processor [2].

The watering system on field and sending the outcomes to the agriculturist utilizing coded signs to a cell phone which by implication controls the whole agriculture watering system framework[3]. The processor or the controller acts as a focal center for working of the robotized process after it has been launched by the SMS based gadget lastly exhibits the yield to the gadget. 
Block Diagram

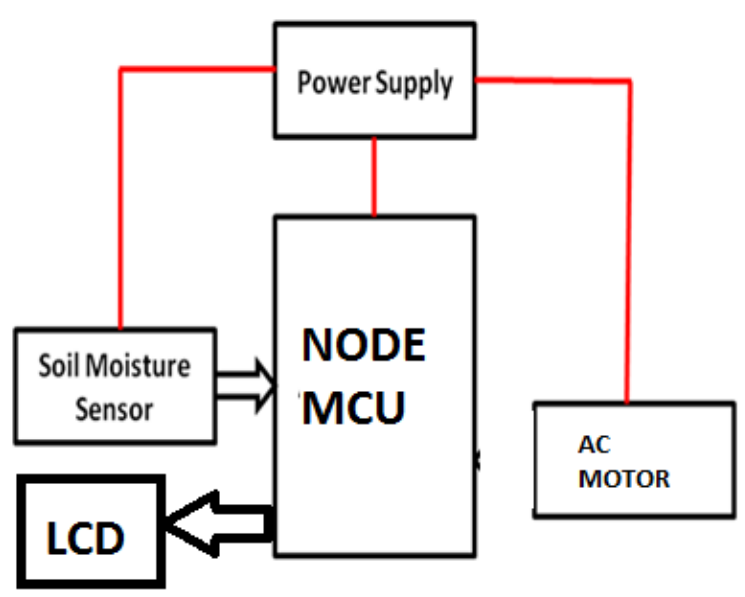

Figure 1: Block Diagram of Smart Irrigation System.

\section{PROBLEMS ON IRRIGATION SYSTEM}

In agriculture system poor supply consistency or managing of waste water. In this irrigation leads to increased soil salinity, build up of toxic salts on the soil surface. Fields or crops should be situated lot of distance from your home. So Wide travel required, also several times in a day to start and stop the irrigation water pumps [4]. Main drawback is more man power required.

\section{METHODOLOGIES IN FARM MONITORING}

Based on NODEMCU i.e. system works by using a mobile Notification. The system as shown in fig. 2 is totally automated. Easy to operate and SMS detect water availability in Pumps. Moisture Sensor module read moisture information like low/high moisture level of soil. It gives a signal to the controller [5]. Controller then gives a signal to the called mobile, by pressing call receiving button microcontroller get signal to turn on the valve. When the moisture level is sufficient, the sensor senses information transfer to the Microcontroller. Relay gets open and the water pump becomes turn off. This information is continuously monitoring in smart phone through Ubdots clouds [6].

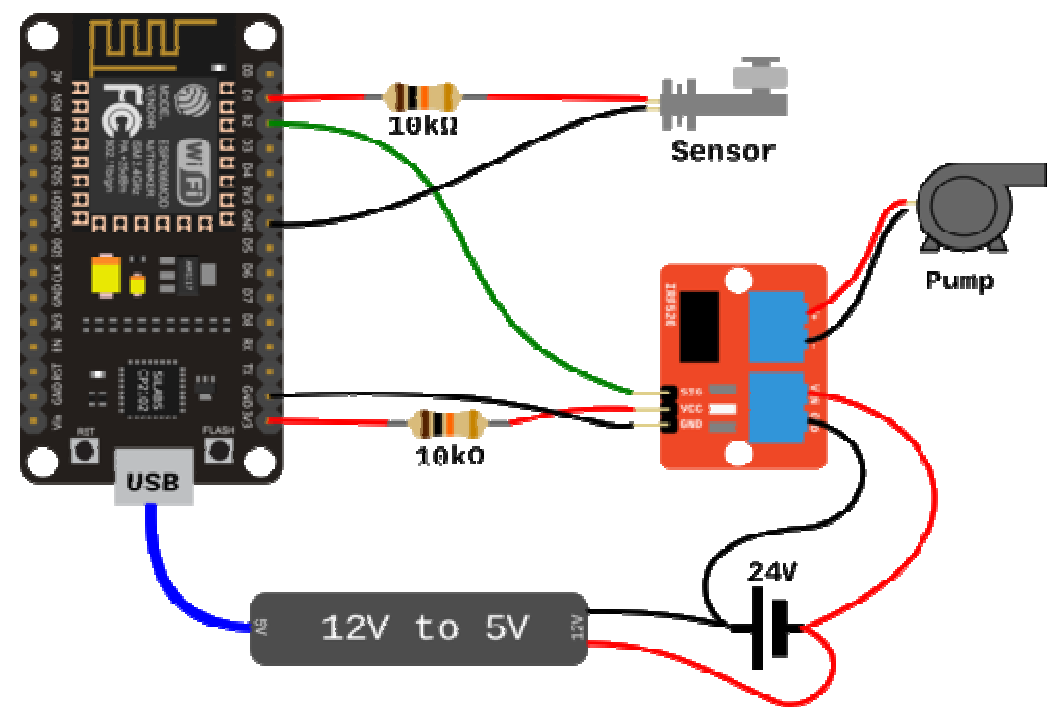

Figure 2: Circuit Diagram of Irrigation System. 
The proposed prototype can help in reducing hard work of smart irrigation system due to on/off valves manually, cost and save time. By using soil moisture sensor module and solenoid valve make a smart irrigation system[7]. NodeMcu based automatic watering system has been designed and tested successfully by part of second.

\section{HARDWARE DESCRIPTION}

\section{Node MCU}

NodeMCU (ESP 8266) as shown in fig.3 is an open-source software and hardware development kit. It is used to build IoT products. It includes firmware that runs on the ESP8266 Wi-Fi SoC from Express if Systems, and hardware which is based on the ESP-12 module. The firmware uses the Lua scripting language [8]. This NodeMCU MicroController Unit is very inexpensive System-on-a-Chip.

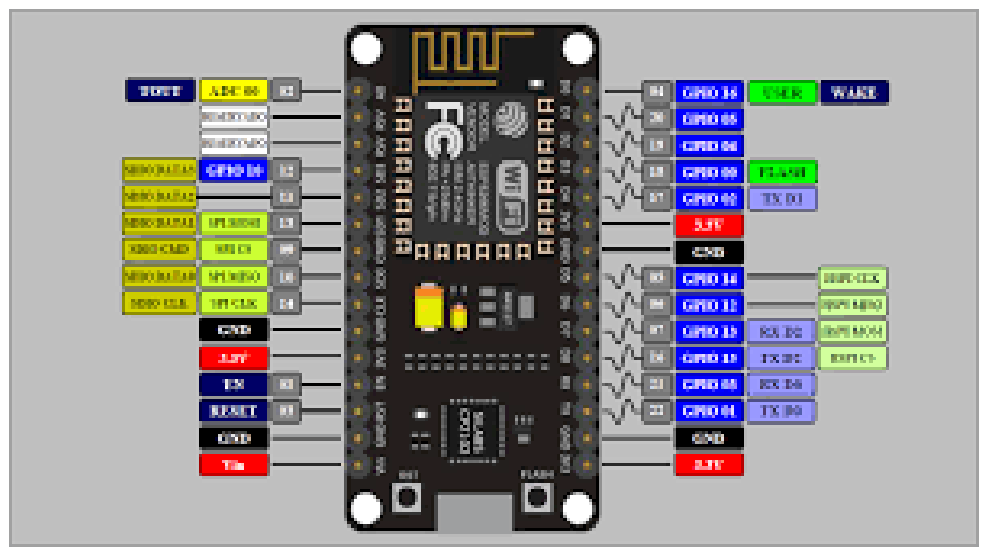

Figure 3: Node MCU.

\section{Channel Relay Module}

The 5V 4Ch Relay as shown in fig.4 interfacing Module system with 15-20mA driver current which can be used to control high current, voltage relays that work under AC250V 10A or DC30V 10A. Loads Lights, fans, motor, solenoid valves etc [9]. It is intended to interface with controller like Raspberry Pi, Arduino nano, Arduino Uno etc. It also have inbuilt LED to indicate the relay status.

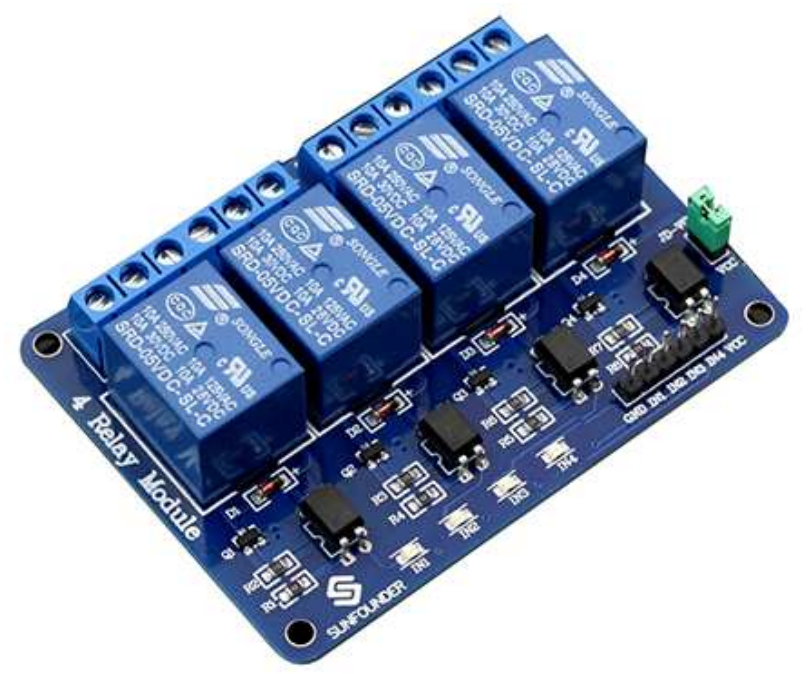

Figure 4: 4Ch Relay Interfacing Module. 


\section{Solenoid Valve}

A solenoid valve as shown in fig. 5 is an electrically controlled valve which has electric coil with a movable ferromagnetic core at center position. Magnetic field is created when an electric current pass through the coil. This Solenoid valve is an electromechanically operated valve and it has different characteristics of the electric current they use. Magnetic field strength also they generate, this mechanism is used to regulate the fluid they control [10]. It is operated under $12 \mathrm{~V}$ DC Current: 250mA - Pressure: 0.02 - 0.8Mpa.

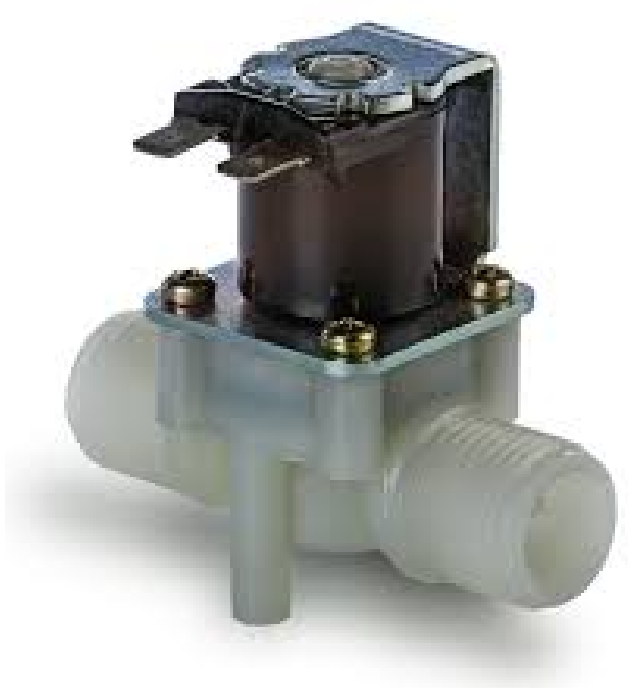

Figure 5: Solenoid Valve.

\section{Submersible Pump}

Ideally used for lifting water and circulation for decoration and domestic purpose. It is submersible pump as shown in fig. 6 and ideally used for air cooler and for coolant transferring application. It is also used for water curtain. single phase. There is an maximum water in the underground of earth, the pump begins to pull water through distribution pipe lines. These pipe lines are located at the top and interconnected with solenoid valves.

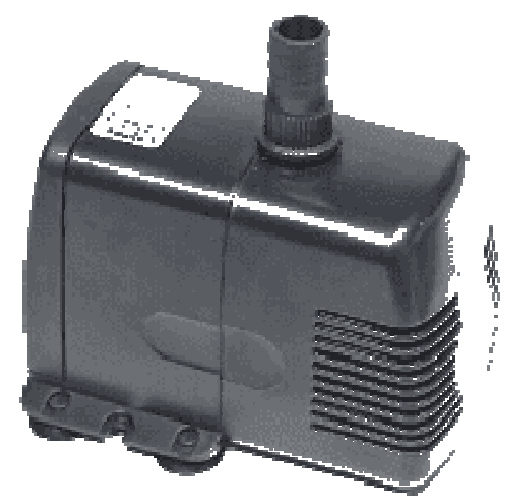

Figure 6: Submersible Pump.

\section{Soil Moisture Sensor Module}

Soil moisture sensor module is used for detect soil moisture and also measures the contented of water inside the soil. This system provides us the moisture level as $\mathrm{O} / \mathrm{P}$. The module has both digital and analog outputs and a potentiometer to adjust the threshold level. 


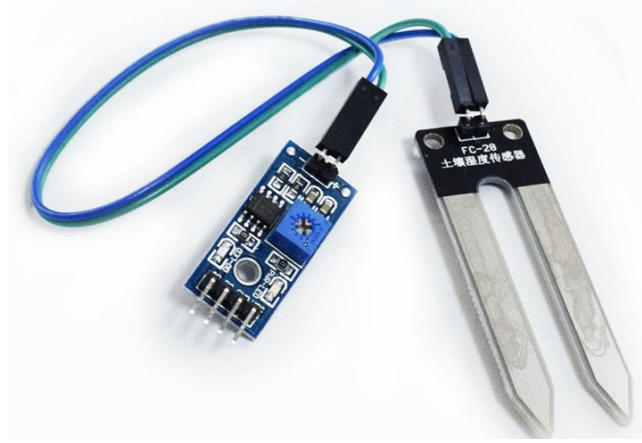

Figure 7: Soil Moisture Sensor Module.

\section{RESULTS AND DISCUSSION}

Here we are building an IoT based Irrigation System as shown in fig.7 using ESP8266 NodeMCU Module and Soil moisture Sensor module. It will not only automatically irrigate the water based on the moisture level in the soil but also send the Data to Ubdots clouds Server to keep track of the land condition [11]. This project uses a solenoid valve to supply the water to the plants. You can change the moisture value at which the solenoid valve should turn on according to your plant's requirement. The complete system through the internet control the motor in the field as shown in fig.8, 9 .

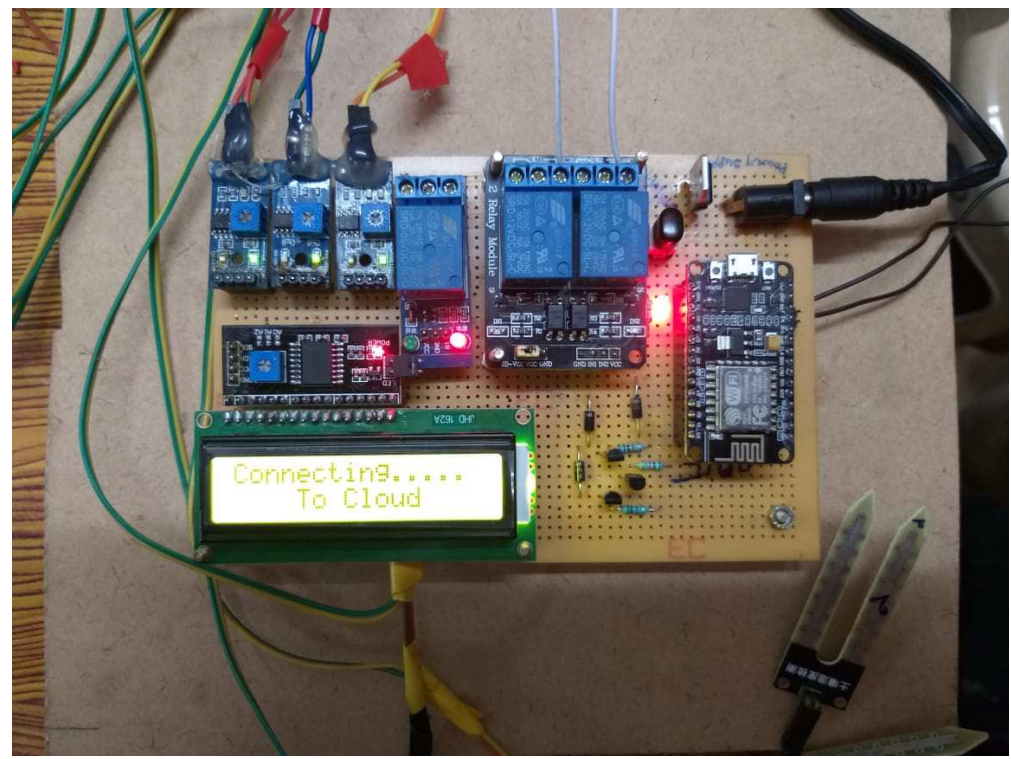

Figure 7: Smart Irrigation System.

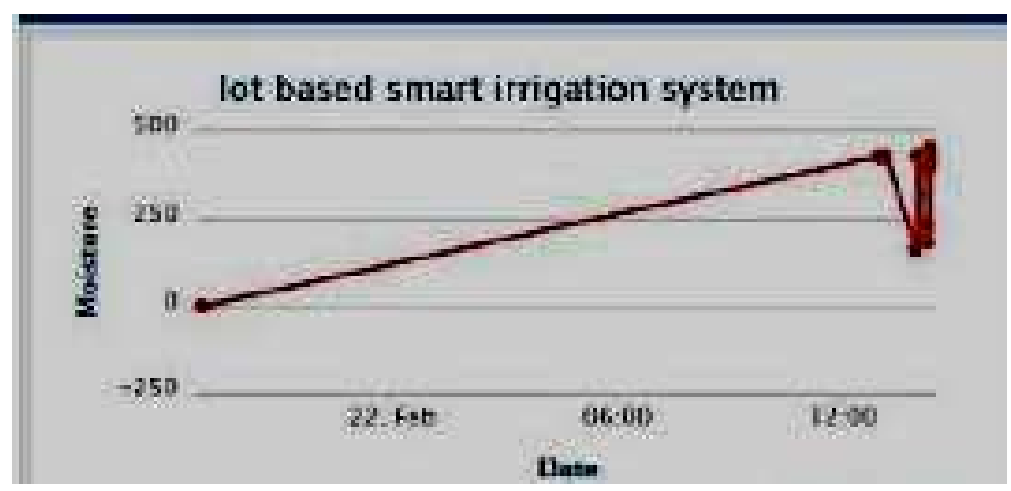

Figure 8: IoT Based Irrigation System Cloud Data. 


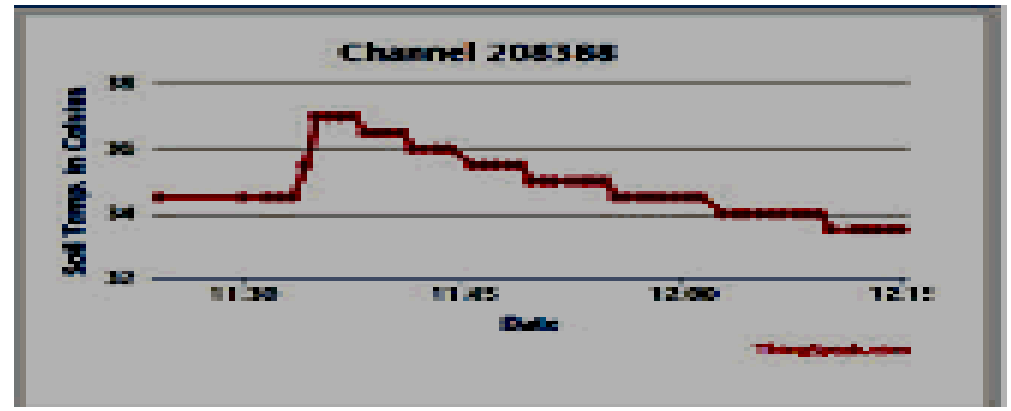

Figure 9: Monitoring Soil Parameters.

\section{CONCLUSIONS}

This paper contains five point by point similar investigation of notification-based agriculture smart irrigation system approach. It gives a neat gritty investigation of the preferences and detriments of the different advances proposed by the frameworks in the papers under study The main aim of this work relies on modernizing the agricultural world by using IoT, hardware components [12]. Agriculture is the backbone of any country and high priority to be given to solve any challenges in this field. So, a framework is developed with SMS, microcontroller, water pump and sensors to irrigate the soil. Parameters like temperature, soil wetness and air wetness sampled by the controller can even be sent to the laptop or mobile by a SMS. Finally, we conclude that automatic irrigation system is more efficient than scheduled irrigation process.

\section{REFERENCES}

1. Chan, M., Campo, E., Esteve, D., Fourniols, J.Y., "Smart homes-current features and future perspectives," Maturitas, Vol. 64, issue 2, pp. 90-97, 2009.

2. Das, S.R., Chita, S., Peterson, N., Shirazi, B.A., Bhadkamkar, M., “Home automation and security for mobile devices," IEEE PERCOM Workshops, pp. 141-146, 2011.

3. S.D.T. Kelly, N.K. Suryadevara, S.C. Mukhopadhyay, "Towards the Implementation of IoT for Environmental Condition Monitoring in Homes", IEEE, Vol. 13, pp. 3846- 3853, 2013.

4. Sirsath N. S, Dhole P. S, Mohire N. P, Naik S. C\&Ratnaparkhi N.S, "Smart Agriculture Using Cloud Network and Mobile Devices".

5. Yang Guang, Geng Guining, Du Jing, Liu Zhaohui, Han He, "Security threats and measures for the Internet of Things", Qinghua Daxue Xuebao/Journal of Tsinghua University, Vol. 51, 2011.

6. Kun Gao, Qin Wang, Lifeng Xi, "Controlling Moving Object in the Internet of Things.

7. IJACT:International Journal of Advancements in Computing Technology, 2.Vol. 4, No. 5, pp. 83-90, 2012.

8. Xun-yi Ren, Lin-juan Chen, Hai-shan Wan, "Homomorphic Encryption and Its Security Application", JDCTA: International Journal of Digital Content Technology and its Applications, Vol. 6, No. 7, pp. 305- 311, 2012.

9. Ken Cai." Internet of Things Technology Applied in Field Information Monitoring”, Advances in information Sciences and Service Sciences AISS, Vol.4, No.12, pp.405-414, 2012.

10. Zhao Xing, Liao Guiping, Shi Xiaohui, Chen Cheng and Li Wen. "Construction of agricultural service mode in IOT and cloud computing environment” [J]. Journal of Agricultural Mechanization Research, Vol.4 pp.142-147, 2012.

11. Li Hang, Chen Houjin, Key technology and application prospect of the internet of things, Forum on Science and Technology in China, 2011 
12. Mo Lianguang, Study on Supply-Chain of Agricultural Products Based on IOT, 2014 Sixth International

13. Samad, Abdul, and Anwaar Mohyuddin. "Social Implication of Water Distribution through Canal Irrigation System: Case Study of a Saraiki Village in Southern Punjab." IMPACT: International Journal of Research in Applied, Natural and Social Sciences (IMPACT: IJRANSS) 1.3 (2013): 91-96.

14. Velusamy, R. "Problems and Prospects of Adoption of Drip Irrigation System in Tamil Nadu." International Journal of Agricultural Science and Research (IJASR) 8.3 (2018):127-134

15. Reddy, K. Hema Narayana, K. Anil Kumar, and M. V. Ramana. "Design and Development of Drip Irrigation System Software in Visual Basic." International Journal of Agricultural Science and Research (IJASR) 7.4 (2017): 339-346.

16. Bowlekar, A P, and P R Kolhe. "ICT Tool-to Design Drip Irrigation System Calculator for Agricultural Crops." International Journal of Agricultural Science and Research (IJASR) 6.5 (2016):177-188 

